\title{
Conception of a complex window design method
}

\author{
Arsenii Tikhomirov ${ }^{1}$, Aleksandr Konstantinov $^{1,{ }^{*}}$, Ksenia Kurushkina $^{1}$ and Maya Lambias \\ Ratnayake $^{1}$ \\ ${ }^{1}$ Moscow State University of Civil Engineering, 129337 Yaroslavskoe shosse, 26, Moscow, Russia
}

\begin{abstract}
Windows are an essential part of almost every civil building. The existing approach for designing windows is based on ensuring minimum requirements to provide natural lighting functions, thermal protection, etc. This approach does not take into account the interrelationship of certain technical characteristics of windows (for example, heat and lighting characteristics). This leads to the appearance of typical problems at the stage of operating the building (insufficient day light, poor ventilation, etc.). In this work, an analysis of functional and technical requirements of windows of civil buildings was conducted. The review of modern researches of optimal window designs and interrelation of certain technical characteristics of window between themselves was conducted. On the basis of this analysis, the concept of a new complex window design method was proposed. This method is based on the fact that windows are both bearing and enclosing elements of the building. The use of this method will create the standard design solutions of windows for civil buildings of different functional purposes and different climatic areas of construction.
\end{abstract}

\section{Introduction. Functional and technical requirements of windows of civil buildings}

As a structural element of the building windows perform many functions (figure 1). Windows define the architectural appearance of the building. However, their main functional purpose is to provide day light in to the premises of the building [1,2]. In addition, windows provide thermal protection to the buildings, acoustic protection and in some cases, natural ventilation of premises. Thus, windows are an important component in the formation of a microclimate within the premises.

\footnotetext{
*Corresponding author: apkonst@yandex.ru
} 


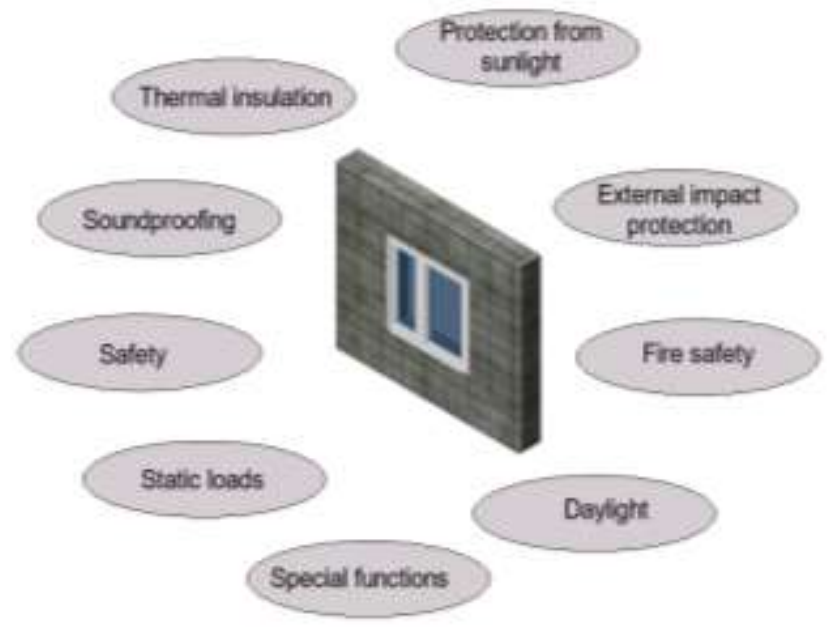

Fig. 1. Technical requirements for window constructions of civil buildings

When designing windows, it is necessary to take into account features of their work, both of the load-bearing and enclosing elements of the building under the impact of various loads and influences (figure 2).

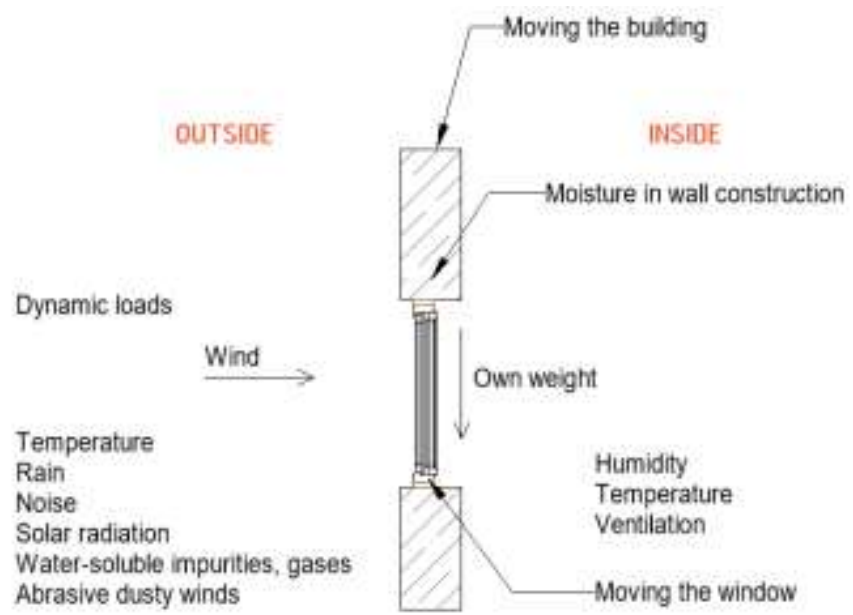

Fig. 2. Loads and impacts on windows of civil buildings

Currently, at the stage of architectural and construction design of civil buildings the selection of windows is based on, as a rule, the following parameters:

- the area of window openings and their location

- the area of window openings and their location on the facades of the building;

- light transmission of windows;

- resistance to heat transfer of windows; temperature on the surface of profile elements and translucent filling;

- air permeability of windows;

- soundproofing of windows.

An important factor affecting the design of the windows are the technological features of their manufacture and installation. As a constructional element of a building a window is a multi-component structure. Windows consist of a window unit, joint seams, fasteners, etc. 
Each of these elements must be calculated separately, they affect the overall characteristics of the window. However, as a rule, technological limitations in production of windows are not considered by designers when assigning their design solutions. As a rule, now window designs are made on the basis of the minimum requirements for each of the parameters. The mutual influence of these parameters on each other is not taken into account. This approach to designing windows leads to the fact that in many cases at the operational stage windows do not fully perform their functions. The purpose of this work is to justify a new approach to window designs. This justification will be given on the basis of a review of modern scientific research to find the optimal design of windows and analyzing the mutual influence of characteristics of the windows on each other.

\section{Reviewing modern research to find the optimal window design and the relationship of window characteristics}

Currently, studies on this issue are conducted in the direction of finding the optimal design of windows from the position of providing their functions such as day light and thermal protection $[3,4]$.

The investigations are conducted mainly from the standpoint of the concept of sustainable construction and considering the life cycle of the window [5-14].

Most of the work is related to the analysis of impact of windows on the energy efficiency of the buildings. At the same time, taking into account the issues of improving energy efficiency of the windows, improving the quality of the indoor environment - providing natural lighting, ventilation [15-22].

Works on searching optimal window designs are conducted. They are associated with optimizing the structural solutions of windows and building facades, and aimed at finding the optimal thermal characteristics taking into account the climate [23-26], reducing investment and operating costs [27-32].

Some studies are related to the concept of lean manufacturing. Within the framework of this direction, studies are made to reduce the material consumption of products while maintaining their performance properties [33].

Studies have been conducted on the mutual influence of operational characteristics of windows. They are associated primarily, with the study of the relationship of thermal and light characteristics of windows [34,35], of the optimal ratio of thermal characteristics between windows and walls [36-38], and also of the influence of size of windows and orientation for heat loss [39-41].

\section{The concept of a new approach to design windows}

The analysis of the works showed that among the significant research results (for this work) we can distinguish the following:

- constructive solution of the windows should be selected taking into account the visual comfort of the premises (no glare). At the same time, the use of solar protection will contribute to the energy efficiency of the building, which reduces energy costs (in comparison with the use of air conditioning systems and the use of artificial lighting) $[17,18,34,35]$;

- orientation and thermal parameters of windows should be assigned not only from the conditions of energy efficiency [38], but also to ensure a comfortable temperature near the windows in winter and summer [22,39]; 
- in order to improve energy efficiency (reduce air conditioning costs), the choice of glazing design (including the type of glass used - low-emission, sunscreen) should be made taking into account the reflectivity of the facades [26];

- overall dimensions (including the height of the window sill) should be selected taking into account the facade orientation and climatic conditions of construction [40]. The increase in the size of the windows on the northern facades does not have a significant impact on heat loss, but significantly increases the day light [41];

- for cold climatic conditions, the use of insulation glass units with the low-emission glass (with a high value of the solar factor) on the southern facades contribute to energy efficiency of buildings [42], in the southern regions it is preferable to use glazing with a low solar factor [43];

- thermal characteristics of the windows have a greater impact on energy costs in winter, than on cooling in summer [30];

- the target to search for optimal window designs should take into account the mode of building operation (the load on heating and cooling) and climatic conditions (hours of summer/winter discomfort) [15];

At the same time, these studies are not fragmented and are considered, as a rule, for specific construction conditions. Therefore, they cannot be widely implemented in construction practice.

This requires a different approach to window design. The basis of this approach should be an engineering technique for the appointment of rational design solution of windows for the particular building taking into account the submitted source data:

- climatic parameters of the construction area;

- building parameters (architectural drawing of windows, constructive and volumetricplanning solution, temperature-humidity regime of the premises, operation mode of the facility, etc.);

-complex requirements for window constructions for a particular building;

It is obvious that the introduction of such a methodology will also allow to form the base of standard design solutions for window constructions for standard projects of civil buildings of various functional purposes (multi-storey civil buildings of mass construction, standard projects of general schools and kindergartens, etc.). Similar solutions were developed earlier in the USSR for the development of mass residential structures for various climatic conditions of construction and room sizes [1] (figures 3 and 4).
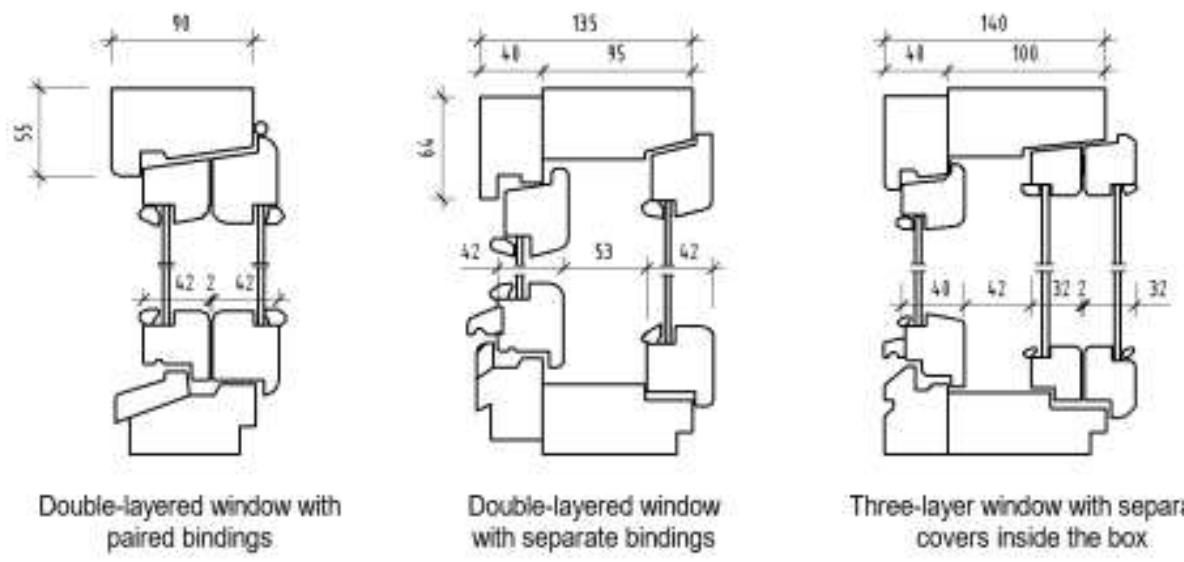

Three-layer window with separate covers inside the box.

Fig. 3. Typical constructive solutions for windows of mass housing construction, used in the 19601980 s in the USSR [1]. 


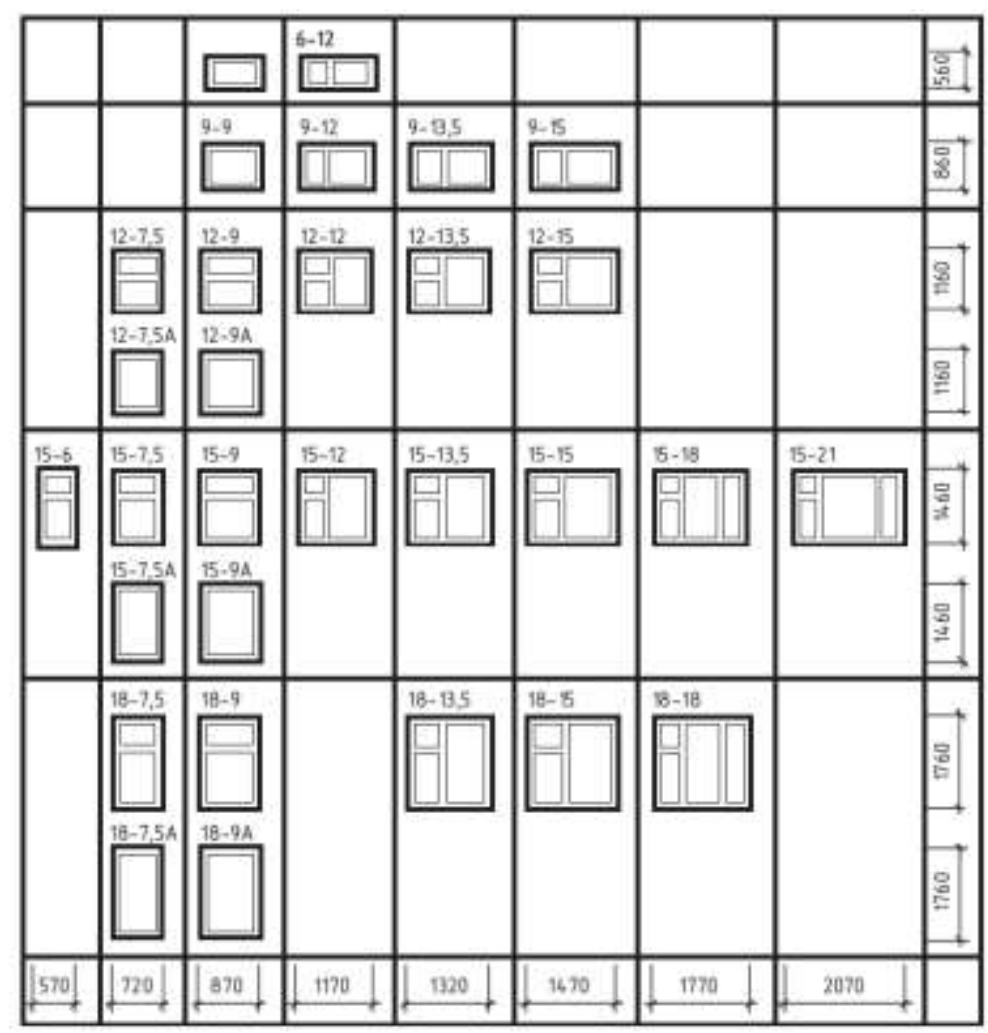

Fig. 4. Typical sizes of wooden window units for residential buildings [1].

In the existing conditions, for the development of the construction industry this methodology should be developed, focusing on the use of digital technologies in construction, primarily on information modeling technologies of buildings. Implementing this method with the help of these technologies will allow automating and optimizing the process of selection of window structures. This will be possible due to a more accurate analysis of the initial base which affects the selection of window structures, the automatic design of window structures and the use of a database of standard design solutions for windows. These technologies need to be implemented at all stages of the life cycle: design, tender, construction, operation. Information models of window designs created by window manufacturers already exist, which simplifies the work with the information model of the building. The application of this technique will simplify the process of designing window structures, improve the quality of design solutions and reduce the number of errors, both at the design stage and at the operational stage.

\section{Conclusions}

As noted above, a review of existing studies on the relationship between the performance of windows shows that existing studies are not comprehensive and consider only the work of windows as building envelopes.

Studies of the modern windows types (and other types of translucent structures) as loadbearing structures were practically not performed $[44,45]$. It is obvious that there is also a relationship between the strength/ deformation and enclosing properties of windows. 
For application of the proposed method in construction practice, it is also necessary to perform the following additional studies:

- the formation of complex requirements for windows on the basis of existing requirements of regulatory documentation, but taking into account their work as bearing and enclosing building elements as well as analyzing typical design errors and operational problems of such structures;

- evaluating the interrelations between key design characteristics of windows among themselves;

- developing criteria for choosing the optimal design solutions for the given construction conditions.

The analysis of the existing approach of window designs showed that it does not take into account the issue of mutual influence of individual technical characteristics of windows on each other.

The overview of works on research of this question shows, that the research focuses primarily on the study of enclosing properties of the windows. It is necessary to change the approach to designing windows. At the same time, one of the most urgent tasks is to create a comprehensive engineering method for selecting rational design solutions of windows in relation to the specified climatic conditions of construction and building design features.

\section{References}

1. I. Boriskina, A. Plotnikov, A. Zaharov, Design of modern window systems for civil buildings (2008)

2. I. Boriskina, Buildings and Structures with Translucent Facades and Roofs. Theoretical Bases of Designing of Glass Constructions (2012)

3. I. Boriskina, N. Shevod, A. Plotnikov, Modern translucent constructions for civil buildings. Designer handbook (2005)

4. H. Ye, XC. Meng, B. Xu, Energy and Buildings 49, 164-172, (2012)

5. H. Ye, XC. Meng, LS. Long, B. Xu, Renewable Energy 55, 448-455 (2013)

6. J.L. Blizzard, L.E. Klotz, Design Studies 33(5), 456-479 (2012)

7. S. Carlisle, E. Friedlander, International Journal of Life Cycle Assessment 21(11), 1645-1657 (2016)

8. A. Invidiata, E. Ghisi, Journal of Cleaner Production 133, 1371-1383 (2016)

9. M.D. Yang, M.D. Lin, Y.H. Lin, K.T. Tsai, Applied Thermal Engineering 111, 1255 1264 (2017)

10. M.M. Tahmasebi, S. Banihashemi, M.S. Hassanabadi, Procedia Engineering 21, 820828 (2011)

11. S. Citherlet, F. Di Guglielmo. J.B. Gay, Energy and Buildings 32(3), 225-234 (2000)

12. J. Salazar, T. Sowlati, Scandinavian Journal of Forest Research 23(2), 121-132 (2008)

13. J. Salazar, Woodhead Publishing Series in Civil and Structural Engineering 49, 50-527 (2014)

14. A.M. Ghita, M. Barnaure, M.C. Iftode, SGEM 2, 609-614 (2016)

15. H. Stichnothea, A. Azapagic, Conservation and Recycling 71, 40-47 (2013)

16. YL. Lin, SQ. Zhou, W. Yang, C.Q. Li, Sustainability 10(2), 336 (2018)

17. A. Chel, G.N. Tiwari, Applied Energy 86(10), 1956-1969 (2009)

18. M. Amirkhani, V. Garcia-Hansen, G. Isoardi, A. Allan, Energies 10(8), 1126 (2017) 
19. M.B.C. Aries, J.A. Veitch, G.R. Newsham, Journal of Environmental Psychology 30(4), 533-541 (2010)

20. G. Elshafei, A. Negm, M. Bady, M. Suzuki, M.G. Ibrahim, Energy and Buildings 141, 321-332 (2017)

21. C.F. Gao, W.L. Lee, Building and Environment 46(4), 961-969 (2011)

22. X. Chen, HX. Yang, YH. Wang Renewable \& Sustainable Energy Reviews 69, 442460 (2017)

23. A. Stegou-Sagia, C. Angelopoulou, Energy Conversion and Management 48(11), 2844-2852 (2007)

24. Y.H. Lin, K.T. Tsai, M.D. Lin, M.D. Yang, Applied Energy 171, 336-346 (2016)

25. S. Devgan, A.M. Jain, B. Bhattacharjee, Energy and Buildings 42(10), 1841-1861 (2010)

26. J.C. Lam, K.K.W. Wan, C.L. Tsang, L. Yang Energy Conversion and Management 49(8), 2354-2366 (2008)

27. G.K. Kumar, S. Saboor, T.P.A. Babu, Energy Procedia 138, 580-585 (2017)

28. W.M. Wang, H. Rivard, R. Zmeureanu Advanced Engineering Informatics 19(1), 5-23 (2005)

29. E. Znouda, N. Ghrab-Morcos, A. Hadj-Alouane, Energy and Buildings 39(2), 148-153 (2007)

30. F.P. Chantrelle, H. Lahmidi, W. Keilholz, M. El Mankibi, P. Michel, Applied Energy 88(4), 1386-1394 (2011)

31. S. Jaber, S. Ajib, Energy and Buildings 43(11), 3208-3215 (2011)

32. A. Stichnothea, A. Azapagic, Conservation and Recycling 71, 40-47 (2013)

33. M. Bodart, A. De Herde, Energy and Buildings 34(5), 421-429 (2002)

34. A.D. Lee, P. Shepherd, M.C. Evernden, D. Metcalfe, Structures 13, 8-25 (2018)

35. H. Altan, I. Ward, J. Mohelnikova, F. Vajkay, Energy and Buildings 41(1), 36-50 (2009)

36. J. Yao, Building and Environment 71, 24-32 (2014)

37. C. Zhang, L.J. Ong, Proceedings of the 22nd International Conference on ComputerAided Architectural Design Research in Asia (CAADRIA 2017), Protocols, Flows and Glitches, 397-405 (2017)

38. N. Harmathy, Z. Magyar, R. Folic, Energy 114, 302-317 (2016)

39. PZ. Ma, L.S. Wang, NH. Guo, Applied Energy 146, 84-91 (2015)

40. S. Kim, P.A. Zadeh, S. Staub-French, T. Froese, B.T. Cavka, Procedia Engineering 145, 1424-1431(2016)

41. A. M. Koohsari, B.M. Kari, BRIS Journal of Advances in Science and Technology 3, 187-194 (2015)

42. M.L. Persson, A. Roos, M. Wall, Energy and Buildings 38, 181-188 (2006)

43. A.M. Nilsson, A. Roos, Thin Solid Films 517(10), 3173-3177 (2009)

44. P. Ihm, L. Park, M. Krarti, D. Seo, Energy policy 44, 1-9 (2012)

45. A.P. Konstantinov, Science prospects 1(100), 26-31 (2018)

46. A. Konstantinov, L. Ratnayake, E3S Web of Conferences 33, 02025 (2018) 